\title{
Rapid Changes of Thyroid Function in a Young Woman with Autoimmune Thyroid Disease
}

\author{
Christian Trummer Verena Schwetz Felix Aberer Marlene Pandis \\ Elisabeth Lerchbaum Stefan Pilz
}

Division of Endocrinology and Diabetology, Department of Internal Medicine, Medical University of Graz, Graz, Austria

\section{Significance of the Study}

- Hashimoto's thyroiditis and Graves' disease share several pathogenetic features, while a transition between the entities is possible. We present the case of a patient with an unusually rapid transition from hyperthyroidism to hypothyroidism and vice versa within just a few weeks.

\section{Keywords}

Hashimoto's thyroiditis · Graves' disease · Hashitoxicosis · Case report

\section{Abstract}

Objective: A conversion from Hashimoto's thyroiditis to Graves' disease and vice versa leads to diagnostic and therapeutic challenges. Clinical Presentation and Intervention: A 30-year-old female presented with overt hyperthyroidism and negative thyroid-stimulating hormone receptor antibodies (TRAbs). Since hashitoxicosis was assumed, the patient was treated with propranolol. Within the next few weeks, the patient developed severe overt hypothyroidism, which was treated with levothyroxine. However, after several more weeks, she presented with overt hyperthyroidism once again, this time showing elevated TRAbs. Conclusion: We suggest educating patients and physicians to recognize changes in thyroid function and close monitoring of unclear cases of overt hyperthyroidism.

(c) 2019 The Author(s)

Published by S. Karger AG, Basel

\section{KARGER}

E-Mail karger@karger.com www.karger.com/mpp

\section{(9) 2019 The Author(s) \\ Published by S. Karger AG, Basel \\ Karger \\ Open access}

This is an Open Access article licensed under the Creative Commons Attribution-NonCommercial-4.0 International License (CC BY-NC) (http://www.karger.com/Services/OpenAccessLicense), applicable to the online version of the article only. Usage and distribution for commercial purposes requires written permission.

\section{Background}

Hashimoto's thyroiditis (HT) and Graves' disease (GD) are the two most common forms of autoimmune thyroid disorders [1]. While the major autoantibodies in HT are directed against thyroid peroxidase (TPO) and thyroglobulin (Tg), a hallmark of GD is the detection of thyroid-stimulating hormone (TSH) receptor antibodies (TRAbs), even though TPO and Tg antibodies can also be found in approximately $70 \%$ of GD patients. However, TRAbs are only rarely detected in HT patients [2]. Usually, HT requires thyroid hormone replacement therapy with levothyroxine (LT) if certain conditions; e.g., overt hypothyroidism, are present [3]. In patients with GD, beta-adrenergic blocking agents can be used to ameliorate symptoms of hyperthyroidism, while three effective causal treatment options exist: antithyroid drugs, radioactive iodine therapy, and thyroidectomy [4].

Even though HT and GD have long been considered two different entities, a conversion from HT to GD can

Christian Trummer

Division of Endocrinology and Diabetology

Department of Internal Medicine, Medical University of Graz

Auenbruggerplatz 15, AT-8036 Graz (Austria)

E-Mail christian.trummer@medunigraz.at 

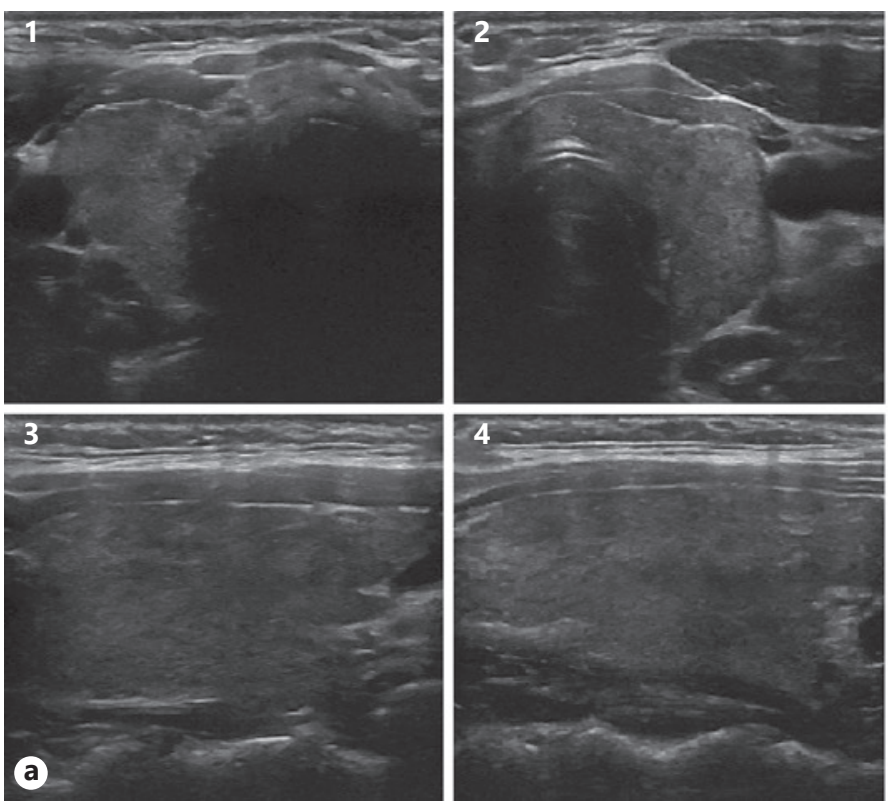
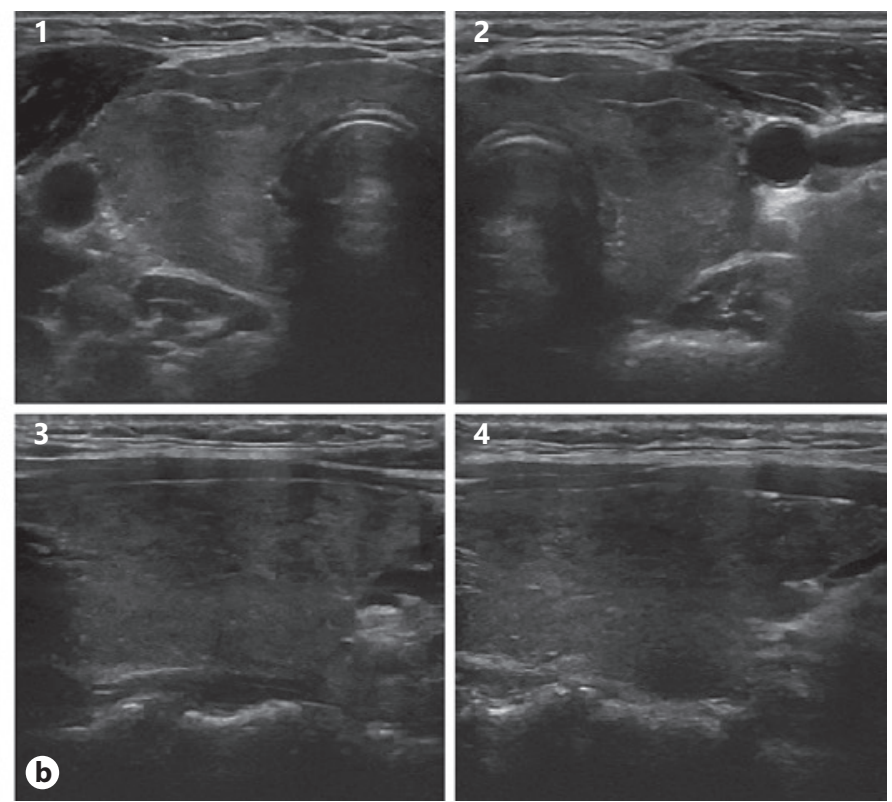

Fig. 1. Sonographic study of the thyroid gland at the patient's first visit (a) and after conversion to overt hyperthyroidism (b). Right thyroid lobe, transverse axis (1); left thyroid lobe, transverse axis (2); right thyroid lobe, sagittal axis (3); left thyroid lobe, sagittal axis (4).

be observed in some rare cases. While the pathophysiological background of this conversion is not yet entirely clear, several reports on the topic have been published [5-7]. As rapid changes in thyroid function may be observed, such cases often lead to diagnostic and therapeutic challenges.

We present the case of a 30-year-old female with autoimmune thyroid disease and a particularly rapid change in thyroid function that fluctuated from hyperthyroidism to hypothyroidism and vice versa within just a few months.

\section{Case Report}

In April 2017, a 30-year-old female patient presented at the endocrine outpatient department of the Medical University of Graz, Austria, for further evaluation of overt hyperthyroidism found during a routine check by her primary care physician. She complained of tachycardia, weight loss, and anxiety. Ten years earlier, the patient was on thyroid hormone replacement therapy for a short period but has not received any thyroid-specific medication since then. No concomitant diseases were reported.

Sonographic examination revealed a thyroid gland with normal vascularization and without any nodular or cystic lesions (Fig. 1). Laboratory parameters showed a suppressed TSH with slightly elevated free triiodothyronine (FT3; $6.7 \mathrm{pmol} / \mathrm{L}$ with a reference range of 3.0-6.3) and normal free thyroxine (FT4). Both
TPO and Tg antibodies were elevated, while TRAbs were within the normal range. Assuming hashitoxicosis with hyperthyroidism, the patient received symptomatic therapy with propranolol and was discharged with an appointment for routine follow-up after approximately 3 weeks.

During the following 2 weeks, the patient presented at our emergency unit twice due to ongoing tachycardia and new onset of chest pain and dyspnea. Possible differential diagnoses of acute coronary syndrome, pulmonary embolism, or pneumothorax were ruled out by biochemical examinations as well as imaging studies (echocardiography, chest X-ray).

When the patient returned to the endocrine outpatient department 4 weeks after her first visit, biochemical tests revealed a normal thyroid function with TSH in the lower normal range $(0.20$ $\mu \mathrm{U} / \mathrm{mL}$, reference range $0.10-4.00$; FT3 and FT4 within the reference range). However, within the next 4 weeks, the patient developed severe overt hypothyroidism with markedly elevated TSH $(100.90 \mu \mathrm{U} / \mathrm{mL})$ and decreased FT4 $(6.2 \mathrm{pmol} / \mathrm{L}$, reference range 9.5-24.0). Therefore, thyroid hormone replacement therapy with $25 \mu \mathrm{g}$ of LT daily was initiated. The comparatively low dose of LT was chosen in view of the patient's clinical presentation with tachycardia and palpitations while also considering the recent low or low-to-normal serum concentrations of TSH. Until this point, the patient was treated with propranolol alone and did not receive any thyroid-specific medication, in particular no thionamides.

Within the following weeks, the patient experienced recurrent tachycardia and chest pain. After about 5 weeks, biochemical tests revealed overt hyperthyroidism once again. At this time, TRAbs were markedly elevated (234.4 U/L, reference range $0-15.0$ ), while $\mathrm{TPO}$ and Tg antibodies increased even further. Consequently, thyreostatic therapy with methimazol was started (beginning with 10 
Table 1. Progression of several thyroid-related parameters, CRP, liver transaminases, and thyroid-related therapy

\begin{tabular}{|c|c|c|c|c|c|c|c|c|c|c|c|c|c|c|c|}
\hline & $\begin{array}{l}\text { Reference } \\
\text { range }\end{array}$ & $\begin{array}{l}\text { April } \\
26\end{array}$ & $\begin{array}{l}\text { April } \\
29\end{array}$ & $\begin{array}{l}\text { May } \\
2\end{array}$ & $\begin{array}{l}\text { May } \\
24\end{array}$ & $\begin{array}{l}\text { June } \\
27\end{array}$ & $\begin{array}{l}\text { July } \\
27\end{array}$ & $\begin{array}{l}\text { August } \\
9\end{array}$ & $\begin{array}{l}\text { August } \\
18\end{array}$ & $\begin{array}{l}\text { August } \\
23\end{array}$ & $\begin{array}{l}\text { August } \\
29\end{array}$ & $\begin{array}{l}\text { September } \\
6\end{array}$ & $\begin{array}{l}\text { September } \\
8\end{array}$ & $\begin{array}{l}\text { October } \\
3\end{array}$ & $\begin{array}{l}\text { October } \\
17\end{array}$ \\
\hline $\mathrm{TSH}, \mu \mathrm{U} / \mathrm{mL}$ & $0.10-4.00$ & 0.00 & & 0.00 & 0.20 & 100.90 & 0.22 & 0.02 & 0.03 & 0.01 & 0.00 & 0.01 & 0.02 & 0.00 & 0.01 \\
\hline $\mathrm{FT} 4, \mathrm{pmol} / \mathrm{L}$ & $9.5-24.0$ & 16.3 & & 16.4 & 11.9 & 6.2 & 19.2 & 23.9 & 24.8 & 21.9 & 15.3 & 11.5 & 10.7 & 17.3 & 16.1 \\
\hline FT3, pmol/L & $3.0-6.3$ & 6.7 & & 6.2 & 4.5 & 3.4 & 7.8 & 10.6 & 13.0 & 10.6 & 6.7 & 5.8 & 5.6 & 7.2 & 6.4 \\
\hline TPO antibodies, $\mathrm{U} / \mathrm{mL}$ & $\leq 60$ & 432 & & & & & & 768 & & 746 & 705 & & & 443 & \\
\hline TRAbs, U/L & $\leq 15$ & 1.5 & & & & & & 234.4 & & 340.4 & 195.7 & 272.1 & & 211.3 & \\
\hline Tg antibodies, $\mathrm{U} / \mathrm{mL}$ & $\leq 60$ & 1,045 & & & & & & $>3,000$ & & $>3,000$ & $>3,000$ & & & & \\
\hline $\mathrm{Tg}, \mathrm{ng} / \mathrm{mL}$ & $\leq 30$ & 1.24 & & & & & & 0.34 & & & & & & & \\
\hline $\mathrm{CRP}, \mathrm{mg} / \mathrm{L}$ & $\leq 5$ & & 1.3 & & & & & & & & & & & & \\
\hline AST, U/L & $\leq 30$ & & 24 & & & & & 32 & & & & 22 & 22 & & 30 \\
\hline ALT, U/L & $\leq 35$ & & 43 & & & & & 52 & & & & 43 & 37 & & 56 \\
\hline
\end{tabular}

TSH, thyroid-stimulating hormone; FT4, free thyroxine; FT3, free triiodothyronine; TPO antibodies, thyroid peroxidase antibodies; TRAbs, thyroid-stimulating hormone receptor antibodies; Tg, thyroglobulin; $\mathrm{CRP}$, C-reactive protein; AST, aspartate transaminase; ALT, alanine transaminase. Therapy: continuous arrow = symptomatic therapy with propranolol; bold arrow = levothyroxine; discontinuous arrow = methimazole.

mg daily), while LT was discontinued earlier. At that time, thyroid sonography showed a hypoechoic organ with significantly elevated vascularization (Fig. 1). Thyroid scintigraphy revealed a diffusely increased uptake of technetium-99m across the entire organ, resulting in an increased total uptake of $10 \%$.

As of February 2018, the patient is still on therapy with methimazol at a reduced dose. Serum concentrations of free thyroid hormones significantly decreased to the normal range, while clinical symptoms ameliorated. During the whole observation period, there were no clinical signs of endocrine orbitopathy or ophthalmopathy.

Table 1 depicts the progression of biochemical parameters as well as therapeutic interventions from April to October 2017.

\section{Discussion}

While the severity and rate of fluctuation in thyroid function as in our case are exceptionally rare, similar cases with conversion from GD to HT or vice versa have been reported in the literature [5-7]. Thus, the existence of such entities needs to be considered by clinicians treating patients with autoimmune thyroid disease, while patients should be educated to recognize possible changes in thyroid function. Furthermore, unclear or typical cases of overt hyperthyroidism warrant close biochemical and clinical monitoring until a definite diagnosis can be made.

However, in some cases, the differential diagnosis of hyperthyroidism can be challenging. In our case, sonographic thyroid studies and TRAb within the reference range initially argued against the presence of GD. Due to the spontaneous normalization of TSH and the free thyroid hormones over the following weeks, radioactive iodine or technetium uptake measurements were initially not performed. As seen in our patient, a relatively higher increase in FT3 when compared to FT4 as well as an in-

Unusually Rapid Change in Thyroid Function creased FT3/FT4 ratio may be indicative of prevalent GD [8]. However, as Doppler studies did not reveal increased vascularization, and both TPO and $\mathrm{Tg}$ antibodies were positive, hashitoxicosis was initially assumed as the cause for hyperthyroidism. After the rapid conversion to overt hypothyroidism, our patient developed overt hyperthyroidism for a second time, this time showing typically elevated TRAbs and increased vascularization in colorcoded Doppler imaging, compatible with GD.

The pathophysiologic background for the conversion from HD to GD is still not entirely understood. Nevertheless, functionally heterogeneous TRAbs exist in both entities; stimulating TRAbs activate the TSH receptor leading to hyperthyroidism, while blocking TRAbs occupy the receptor, hereby causing hypothyroidism [9]. A conversion or quantitative change from blocking to stimulating subtypes, or vice versa, could possibly explain the transformation from one autoimmune thyroid disorder to the other. Indeed, in a study conducted in patients with either blocking or stimulating TRAbs over the course of 10 years, the authors reported a disappearance or change of TRAb subtype in some of the study subjects [10].

\section{Conclusion}

We present the case of a 30-year-old Austrian female patient with unusually rapid conversion from overt hyperthyroidism to overt hypothyroidism and vice versa within only a few weeks. Despite the rarity of such extreme cases, we suggest educating patients to recognize symptoms of changes in thyroid function as well as close clinical and biochemical monitoring of unclear cases of overt hyperthyroidism. 


\section{References}

1 McLeod DS, Cooper DS. The incidence and prevalence of thyroid autoimmunity. Endocrine. 2012 Oct;42(2):252-65.

2 Dong YH, Fu DG. Autoimmune thyroid disease: mechanism, genetics and current knowledge. Eur Rev Med Pharmacol Sci. 2014; 18(23):3611-8.

3 Jonklaas J, Bianco AC, Bauer AJ, Burman KD, Cappola AR, Celi FS, et al.; American Thyroid Association Task Force on Thyroid Hormone Replacement. Guidelines for the treatment of hypothyroidism: prepared by the american thyroid association task force on thyroid hormone replacement. Thyroid. 2014 Dec; 24(12):1670-751.

4 Ross DS, Burch HB, Cooper DS, Greenlee MC, Laurberg P, Maia AL, et al. 2016 American Thyroid Association Guidelines for Diagnosis and Management of Hyperthyroidism and Other Causes of Thyrotoxicosis. Thyroid. 2016 Oct;26(10):1343-421.
5 Wasniewska M, Corrias A, Arrigo T, Lombardo F, Salerno M, Mussa A, et al. Frequency of Hashimoto's thyroiditis antecedents in the history of children and adolescents with graves' disease. Horm Res Paediatr. 2010; 73(6):473-6.

6 Aversa T, Lombardo F, Corrias A, Salerno M, De Luca F, Wasniewska M. In young patients with Turner or Down syndrome, Graves' disease presentation is often preceded by Hashimoto's thyroiditis. Thyroid. 2014 Apr;24(4): $744-7$.

7 Aversa T, Valenzise M, Salerno M, Corrias A, Iughetti L, Radetti G, et al. Metamorphic thyroid autoimmunity in Down Syndrome: from Hashimoto's thyroiditis to Graves' disease and beyond. Ital J Pediatr. 2015 Nov;41(1):87.
8 Chen X, Zhou Y, Zhou M, Yin Q, Wang S. Diagnostic Values of free triiodothyronine and free thyroxine and the ratio of free triiodothyronine to free thyroxine in thyrotoxicosis. Int J Endocrinol. 2018 Jun;2018:4836736.

9 Takasu N, Oshiro C, Akamine H, Komiya I, Nagata A, Sato Y, et al. Thyroid-stimulating antibody and TSH-binding inhibitor immunoglobulin in 277 Graves' patients and in 686 normal subjects. J Endocrinol Invest. 1997 Sep;20(8):452-61.

10 Takasu N, Matsushita M. Changes of TSHstimulation blocking antibody (TSBAb) and thyroid stimulating antibody (TSAb) over 10 years in 34 TSBAb-positive patients with hypothyroidism and in 98 TSAb-positive Graves' patients with hyperthyroidism: reevaluation of TSBAb and TSAb in TSH-receptor-antibody (TRAb)-positive patients. J Thyroid Res. 2012;2012:182176. 